\title{
The effect of common variants in GDF5 gene on the susceptibility to chronic postsurgical pain
}

\author{
Shaoyao Yan, Huiyong Nie, Gang Bu, Weili Yuan and Suoliang Wang* (i)
}

\begin{abstract}
Background: The growth differentiation factor 5 (GDF5) gene regulates the growth of neuronal axons and dendrites and plays a role in the inflammatory response and tissue damage. The gene may also be associated with chronic postsurgical pain. This study aimed to reveal the relationship between SNPs in the GDF5 gene and orthopedic chronic postsurgical pain in Han Chinese population based on a case-control study.

Methods: We genotyped 8 SNPs within GDF5 gene in 1048 surgical patients with chronic postsurgical pain as the case group and 2062 surgical patients who were pain free as the control group. SNP and haplotypic analyses were performed, and stratified analyses were conducted to determine the correlations between significant SNPs and clinical characteristics.

Results: Only rs 143384 in the 5'UTR of GDF5 was identified as significantly associated with increased susceptibility to chronic postsurgical pain, and the risk of A allele carriers was increased approximately 1.35 -fold compared with that of G allele carriers. Haplotypes AGG and GGG in the LD block rs143384-rs224335-rs739329 also showed similar association patterns. Furthermore, we found that rs 143384 was significantly correlated with chronic postsurgical pain in the subgroup aged $\leq 61$ years, subgroup with a BMI $\leq 26$, subgroup with no-smoking or no pain history, and subgroup with a drinking history.

Conclusion: Our study provided supportive evidence that genetic variations in the GDF5 gene are potential genetic factors that can increase the risk of chronic postsurgical pain in the Han Chinese population, but further research is necessary to elucidate the underlying mechanism.
\end{abstract}

Keywords: Chronic postsurgical pain, Single nucleotide polymorphism, GDF5 gene, Case-control study

\section{Background}

Pain is a universal feeling defined as an unpleasant sensory and emotional experience, and it varies considerably between populations for different environmental and genetic factors [1-3]. Although pain is a necessary warning signal of potential harm under certain conditions, chronic postsurgical pain (CPSP) is generally not conducive to postsurgical recovery. Pain is expected to be

\footnotetext{
*Correspondence: znwangdr@163.com

Department of Pain, The First Affiliated Hospital of Xi'an Jiaotong University, No. 277, Yanta West Road, Xi'an, Shaanxi, China
}

reduced with wound healing; however, some patients continue to have persistent pain known as CPSP, which affects 9.2 to $80.0 \%$ of surgery patients [4-6].

Chronic postsurgical pain is influenced by multiple physical factors, and considerable efforts have revealed that genetic variations are associated with the development of CPSP [7, 8]. Damage to neurological tissue during surgery is a prerequisite for CPSP, which elicits an excessive inflammatory response to regulate various inflammatory cytokines; the latter play key roles in the occurrence and maintenance of CPSP [9]. The growth

C C The Author(s). 2021 Open Access This article is licensed under a Creative Commons Attribution 4.0 International License, which permits use, sharing, adaptation, distribution and reproduction in any medium or format, as long as you give appropriate credit to the original author(s) and the source, provide a link to the Creative Commons licence, and indicate if changes were made. The images or other third party material in this article are included in the article's Creative Commons licence, unless indicated otherwise in a credit line to the material. If material is not included in the article's Creative Commons licence and your intended use is not permitted by statutory regulation or exceeds the permitted use, you will need to obtain permission directly from the copyright holder. To view a copy of this licence, visit http://creativecommons.org/licenses/by/4.0/ The Creative Commons Public Domain Dedication waiver (http://creativecommons.org/publicdomain/zero/1.0/) applies to the data made available in this article, unless otherwise stated in a credit line to the data. 
differentiation factor 5 (GDF5) gene, located at 20q11.22 with 4 exons, encodes a secreted ligand of the TGF- $\beta$ superfamily [10]. Its corresponding protein regulates the growth of neuronal axons and dendrites, as well as tissue development, including cartilage and the joint [11], and plays a role in the inflammatory response and tissue damage [12]. Additionally, genome-wide association studies (GWASs) have shown that the GDF5 gene contributes to knee or hip osteoarthritis $[11,13,14]$. Therefore, we hypothesized that the GDF5 gene is associated with CPSP, particularly in orthopedic surgery patients. The skeletal system supports body weight and movement, and studying the prognosis of orthopedic surgery is crucial to improve the daily life quality of patients. Single-nucleotide polymorphisms (SNPs) are common genomic DNA variations in populations, and SNPs located within functional regions of a gene may result in amino acid substitution and gene expression, which may be associated with susceptibility to diseases [15]. The rs143383 locus in the 5'UTR of GDF5 is associated with increased susceptibility to osteoarthritis (including osteoarthritis of the knee, hip and hand) in both Asian and European populations [16-19], and different alleles of rs143383 influence GDF5 gene expression in the whole joint, probably leading to increased susceptibility to osteoarthritis in individuals [20]. However, Shin et al. reported that rs 143383 was not associated with primary knee osteoarthritis in a Korean population [21], and Tsuzou et al. reported a similar finding in Greek Caucasians of no significant differences in the subgroup stratified by sex [22]. Another two SNPs, rs224332 and rs224333, located in the GDF5 gene were identified as related to hip dysplasia in Chinese women [23]. Knee pain is one of the most common musculoskeletal complaints that results in orthopedic surgery, although it is affected by various risk factors, such as sex, age, history of knee injuries, and smoking [24-26]. A recent genome-wide study by Meng et al. suggests that rs143384 in the GDF5 gene is associated with knee pain in the UK Biobank, allele A is a risk factor [27], and SNP rs143384 in the 5'UTR region can affect GDF5 expression [28], indicating that the GDF5 gene is a potential risk factor for orthopedic CPSP.

However, the contribution of the GDF5 gene to CPSP has not been directly elucidated based on biological evidence. Thus, exploring potential correlations between the GDF5 gene and CPSP among different independent populations is necessary to enhance our understanding of the role of the GDF5 gene in CPSP susceptibility. In the current study, we analyzed the genetic correlation of the GDF5 gene with the risk of orthopedic CPSP and explored the risk factors correlated with CPSP in 3110 Han Chinese individuals. Our research aimed to uncover the relationship of SNP variants in the GDF5 gene with orthopedic CPSP susceptibility and provide information to study the mechanisms involved in the etiology of CPSP.

\section{Materials and methods Subjects}

In the present study, we recruited 1048 patients with CPSP as the case group and 2062 patients without CPSP as the control group from the First Affiliated Hospital of Xi'an Jiaotong University and Xi'an Honghui Hospital (all in Xi'an city). All the patients had undergone orthopedic surgery using total intravenous anesthesia; after discharge from the hospital, postsurgical pain was evaluated with cooperation. Patients who had previously undergone surgery, patients who abused pain medications, and patients with severe organic diseases were excluded from this study. All the recruited subjects were Han Chinese individuals. Additionally, to avoid potential population stratification in the study, the subjects who had an immigration history within three generations were not included in the present study. All the patients received patient-controlled intravenous analgesia (PCIA) 5 min before the surgical incision was closed. PCIA comprised fentanyl $(15-20 \mathrm{mg} / \mathrm{kg})$, dexamethasone $10 \mathrm{mg}$, and ondansetron $8 \mathrm{mg}$, which were diluted to $100 \mathrm{ml}$. During hospitalization, flurbiprofen axetil was injected intravenously as a combined analgesic to relieve inflammation $(50 \mathrm{mg}$, twice a day). The same postsurgical pain management team used 11-point pain analog scale (PAS) to measure the severity of pain for all patients to complete the assessment of the pain severity over the surgical site that has persisted for 12 months after the operation. The severity score ranged from 0 to $10(0$ no pain, 10 worst imaginable pain). According to previous studies, we defined patients with a PAS score $>3$ as the CPSP group [29]. Additionally, patients reported their current health status and pain management therapies including use of analgesics during the 12 months after the operation. Demographic and clinical information was collected from the study subjects (Table 1). All the subjects signed informed consent forms, and the study proposal was authorized by the ethics committee of the First Affiliated Hospital of Xi'an Jiaotong University.

\section{SNP selection and genotyping}

To minimize the cost of the experiment while obtaining sufficient analysis data, we selected the tag SNPs in the GDF5 gene for genotyping. First, we extracted all the SNPs with a minor allele frequency (MAF) $\geq 0.01$ in the GDF5 gene. Next, we obtained all the tagged SNPs from the dataset of candidate SNPs based on the criterion of $r^{2} \geq 0.8$. The Sequenom MassARRAY platform was used to genotype the 8 tag SNPs. The relevant information of these tag SNPs is shown in Supplementary Table S1. 
Table 1 Basic characteristics of subjects

\begin{tabular}{llll}
\hline Variation & $\begin{array}{l}\text { Case } \\
(\boldsymbol{n}=\mathbf{1 0 4 8})\end{array}$ & $\begin{array}{l}\text { Control } \\
(\boldsymbol{n}=\mathbf{2 0 6 2})\end{array}$ & $\boldsymbol{P}$ value* $^{*}$ \\
\hline Age (year, mean \pm SD) & $61.1 \pm 7.1$ & $61.1 \pm 7.6$ & 0.95 \\
Gender [n, (\%)] & & & \\
$\quad$ Male & $580(55.3 \%)$ & $1143(55.4 \%)$ & 0.98 \\
$\quad$ Female & $468(44.7 \%)$ & $919(44.6 \%)$ & \\
BMI (mean \pm SD) & $25.97 \pm 1.44$ & $26.06 \pm 1.56$ & 0.11 \\
PAS (mean \pm SD) & $2.27 \pm 0.98(0-3)$ & $5.72 \pm 1.60(4-9)$ & $<\mathbf{0 . 0 1}$ \\
Smoking [n, (\%)] & $250(23.9 \%)$ & $514(24.9 \%)$ & 0.51 \\
Drinking [n, (\%)] & $311(29.8 \%)$ & $642(31.1 \%)$ & 0.40 \\
With prior pain history & $118(11.3 \%)$ & $220(10.7 \%)$ & 0.62 \\
\hline
\end{tabular}

$P A S$ pain analog scale, $S D$ standard deviation

*Pearson $x^{2}$ value

The genomic DNA used for genotyping came from the subject's peripheral blood samples. A Tiangen DNA Extraction Kit was used for all DNA extraction according to the manufacturer's instructions. In order to control the quality of genotyping, the technicians performing genotyping cannot know the case-control label of each sample in advance. In addition, we also conducted random sampling re-examinations on $5 \%$ of the samples. The re-examination results were completely consistent with the initial examination results.

\section{Statistical analyses}

The association analysis of alleles and genotypes between the SNPs in the GDF5 gene and orthopedic CPSP was performed using PLINK v1.9 software under three logistic models (additive, dominant and recessive), as well as the Hardy-Weinberg equilibrium (HWE) of all SNPs in the case and control groups. For allele association analysis, the odds ratio (OR) and 95\% confidence interval $(95 \% \mathrm{CI})$ were calculated to assess the association degree between SNPs in the GDF5 gene and CPSP susceptibility. Statistical analysis for the basic parameters was implemented via Pearson chi-squared $\left(x^{2}\right)$ test and unpaired Student's $t$ test using SPSS 19.0 (IBM Inc.). Haploview v4.2 was used to detect pairwise linkage disequilibrium (LD), and GENECOUNTING v2.2 was used to estimate the haplotype frequencies and association analysis by permutation testing. $P<0.05$ was set as the threshold of statistically significant difference.

\section{Results}

\section{Essential features of the participants}

Table 1 demonstrates the essential features of the participants in our study. The case group contained 1048 CPSP individuals, and the control group of 2062 individuals without CPSP was similar in age, with mean ages of $61.1 \pm 7.1$ and $61.1 \pm 7.6$ years, respectively. In the case group, $44.7 \%$ of cases were male and $55.3 \%$ were female,
Table 2 Multiple comparisons for correlation between GDF gene SNP rs143384 and CPSP risk

\begin{tabular}{llll}
\hline & Case $(\mathbf{n}=\mathbf{1 0 4 8})$ & Control $(\mathbf{n}=\mathbf{2 0 6 2})$ & $\boldsymbol{P}^{*}$ \\
\hline $\begin{array}{llll}\text { Gender: male } \\
\text { GG }\end{array}$ & $20(1.91 \%)$ & $63(3.06 \%)$ & 0.06 \\
GA/AA & $560(53.43 \%)$ & $1079(52.32 \%)$ & \\
Female & & & \\
GG & $14(1.34 \%)$ & $46(2.23 \%)$ & 0.08 \\
GA/AA & $454(43.32 \%)$ & $874(42.39 \%)$ & \\
Age: $\leq 61$ years & & & \\
GG & $12(1.15 \%)$ & $48(2.33 \%)$ & 0.02 \\
GA/AA & $432(41.22 \%)$ & $816(39.57 \%)$ & \\
$>$ 61 years & & & 0.17 \\
GG & $22(2.10 \%)$ & $61(2.96 \%)$ & \\
GA/AA & $582(55.53 \%)$ & $1137(55.14 \%)$ &
\end{tabular}

BMI: $\leq 26$

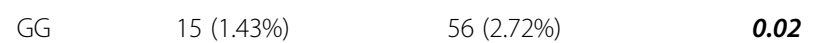

GA/AA $\quad 464(44.27 \%) \quad 854(41.42 \%)$

$>26$

GG $\quad 19(1.81 \%) \quad 53(2.57 \%) \quad 0.22$

GA/AA $\quad 550(52.48 \%) \quad 1099(53.30 \%)$

Lifestyle: smoking

$\begin{array}{lll}\text { GG } & 8(0.76 \%) & 29(1.41 \%) \\ \text { GA/AA } & 242(23.09 \%) & 485(23.52 \%)\end{array}$

No-smoking

$\begin{array}{llll}\text { GG } & 26(2.48 \%) & \mathbf{0 . 0 3}\end{array}$

GA/AA $\quad 772(73.66 \%) \quad 1468(71.19 \%)$

Drinking

$\begin{array}{llll}\text { GG } & 8(0.76 \%) & 37(1.79 \%) & 0.03\end{array}$

GA/AA $303(28.91 \%) \quad 605(29.34 \%)$

No-drinking

GG $\quad 26(2.48 \%) \quad 72(3.49 \%)$

GA/AA $711(67.84 \%) \quad 1348(65.37 \%)$

Prior pain history

$\begin{array}{lll}\text { GG } & 2(0.19 \%) & 9(0.44 \%) \\ \text { GA/AA } & 116(11.07 \%) & 211(10.23 \%)\end{array}$

No prior pain history

\begin{tabular}{llll} 
GG & $32(3.05 \%)$ & $100(4.85 \%)$ & 0.02 \\
GA/AA & $898(85.69 \%)$ & $1742(84.48 \%)$ & \\
\hline
\end{tabular}

*P value was calculated by chi-square test; the significant value was shown in bold italics

and the corresponding percentages were $44.6 \%$ and $55.4 \%$ in the control group, respectively. The rates with a history of smoking, drinking, and prior pain in the case group vs control group were $23.9 \%$ vs $24.9 \%, 29.8 \%$ vs $31.1 \%$ and $11.3 \%$ vs $10.7 \%$, respectively. Statistical analysis suggested no significant differences in the 
Table 3 The results of single SNP association analyses of rs 143384 and CPSP risk

\begin{tabular}{|c|c|c|c|c|c|c|c|c|c|c|}
\hline \multirow{2}{*}{$\begin{array}{l}\text { Group } \\
\text { rs143384 }\end{array}$} & \multirow[t]{2}{*}{ HWE $P$} & \multicolumn{2}{|c|}{ Allele number (\%) } & \multirow[t]{2}{*}{ Allelic $P^{*}$} & \multicolumn{3}{|c|}{ Genotype number (\&) } & \multicolumn{2}{|c|}{ Genotypic $P^{*}$} & \multirow{2}{*}{$\begin{array}{l}\mathrm{OR}^{* *} \\
(95 \% \mathrm{Cl})\end{array}$} \\
\hline & & G & $A$ & & GG & GA & $\mathrm{AA}$ & Additive & $3.92 E-05$ & \\
\hline Case $(n=1048)$ & 0.61 & $393(18.75 \%)$ & $1703(81.25 \%)$ & $7.85 E-06$ & 34 (3.24\%) & 325 (31.01\%) & $689(65.75 \%)$ & Dominant & $2.32 E-05$ & 1.35 \\
\hline Control $(n=2062)$ & 0.43 & 977 (23.69\%) & 3147 (76.31\%) & & 109 (5.29\%) & $759(36.81 \%)$ & $1194(57.90 \%)$ & Recessive & 0.011 & $(1.18-1.54)$ \\
\hline
\end{tabular}

HWE Hardy-Weinberg equilibrium, $O R$ odds ratio, $\mathrm{Cl}$ confidence interval

${ }^{*}$ The significant $P$ value was shown in bold italics; ${ }^{* *} \mathrm{OR}$ is for the risk allele $\mathrm{A}$ of rs143384

distribution of age, gender, lifestyles (smoking or drinking), or pain history $(P>0.05)$ between the two groups. Pain severity measured by PAS is an important component of the CPSP diagnosis, which is set as 11 grades from 0 to 10 (0 no pain, 10 worst imaginable pain); thus, the case group included individuals with scores of 4-10, and the control group included individuals with scores of $0-3$. The PAS scores were statistically significant between the two groups $(P<0.001)$.

\section{Single SNP analysis between the GDF5 gene and CPSP risk}

The allelic and genotypic frequency distributions of the 8 SNPs in the GDF5 gene are shown in Table 2 and Supplemental Table S2. All 8 selected SNPs in the GDF5 gene were in HWE in the case and control groups $(P>$ $0.05)$, while the single SNP association analyses indicated that only rs143384 (G/A) was significantly different between the case and control groups. The minor allele $G$ frequencies were $18.75 \%$ and $23.69 \%$ in the case and control groups, respectively, while the CPSP risk was increased in subjects with the A allele of rs143384 compared with that in $\mathrm{G}$ allele carriers $(\mathrm{OR}=1.35 ; 95 \% \mathrm{CI}$ $1.18-1.54 ; P=7.85 \mathrm{E}-06$ ), indicating that the A allele at rs143384 was a risk factor for CPSP. Moreover, the genotype frequency was $3.24 \%$ for GG, 31.01\% for GA, and $65.75 \%$ for AA in the case group and $5.29 \%$ for GG, $36.81 \%$ for GA, and $57.90 \%$ for AA in the control group. The genotype frequencies of rs143384 were significantly different between the CPSP group and no-CPSP group under the three models $(P=3.92 \mathrm{E}-05,2.32 \mathrm{E}-05$, and 0.011 for the additive, dominant, and recessive models, respectively). Thus, genotypic analyses confirmed association signals similar to those of allelic analyses (Table 2).

\section{Stratified analyses between rs 143384 and CPSP risk}

We also evaluated the correlation between the GDF5 gene SNP rs143384 and CPSP risk in different subgroups (Table 3). No significant association was found between rs143384 GG vs GA\&AA and CPSP risk for the male and female subgroups $(P>0.05)$. Regarding age stratification, rs143384 GG vs GA\&AA was significantly associated with CPSP risk for those aged $\leq 61$ years $(P=0.02)$, and no significant difference was observed in the genotype distribution within the advanced age subgroup ( $>61$ years). In the subgroup with $\mathrm{BMI} \leq 26$, the genotype frequencies of rs143384 were significantly different between the case and corresponding control samples $(P=0.02)$, and similar results were found in the no-smoking subgroup, drinking subgroup, and subgroup without a pain history. We also explored the relationship between rs143384 and the PAS score in our samples. The genotype distribution of rs143384 was associated with different PAS scores (Table 4; $P=0.0162$ ).

\section{Haplotype-based analyses}

The 8 tag SNPs selected in this study map a $12.7-\mathrm{kb}$ genomic region; hence, we examined the LD structure of these loci to perform haplotype-based association analyses. Two strong LD blocks (block 1: rs8117190rs6058244; block 2: rs143384-rs224335-rs739329) were identified (Fig. 1), haplotypic associations of block 2 were observed with global $P<0.000001$, four haplotypes were found in block 2 (Table 5), and the haplotypes AGG and GGG showed significant differences between the CPSP and control groups $(P=0.00012$ and 0.00010 , respectively).

\section{Discussion}

Numerous studies have focused on the effect of gene polymorphisms on complex diseases in recent years and have

Table 4 The correlation between GDF5 gene SNP rs143384 genotypes and PAS score

\begin{tabular}{llll}
\hline NRS & \multicolumn{2}{l}{ Genotype } & $P^{*}$ \\
\cline { 2 - 3 } & GA/AA & GG & \\
\hline 0 & $179(5.76 \%)$ & $22(0.71 \%)$ & \\
1 & $165(5.31 \%)$ & $23(0.74 \%)$ & \\
2 & $496(15.95 \%)$ & $32(1.03 \%)$ & \\
3 & $1113(35.79 \%)$ & $32(1.03 \%)$ & \\
4 & $268(8.62 \%)$ & $26(0.84 \%)$ & \\
5 & $278(8.94 \%)$ & $1(0.03 \%)$ & \\
6 & $176(5.66 \%)$ & $1(0.03 \%)$ & \\
7 & $105(3.38 \%)$ & $1(0.03 \%)$ & \\
8 & $103(3.31 \%)$ & $1(0.03 \%)$ & \\
9 & $84(2.70 \%)$ & $4(0.13 \%)$ & \\
\hline$*$ P v & &
\end{tabular}

* $P$ value was calculated by Student's $t$ test; the significant value was shown in bold italics 


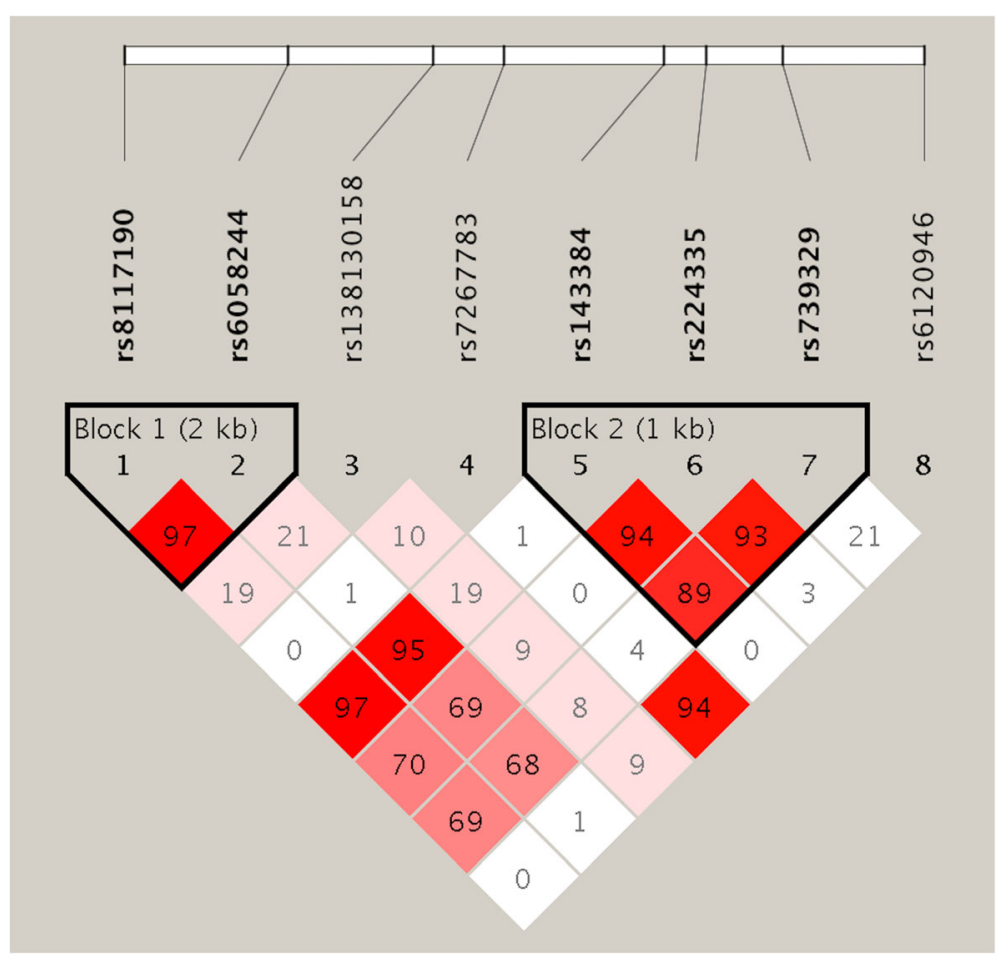

Fig. 1 The linkage disequilibrium (LD) among 8 SNPs in GDF5 gene. Values of D' are indicated in each cell

shown that the GDF5 gene contributes to various osteoarthritis forms $[11,13,14]$. Studies have proven that many pathological changes in osteoarthritis result from chronic low-grade inflammation mediated by inflammatory cytokines such as TNF- $\alpha$ and IL-1 $\beta$ [30]. Decreased GDF5 expression in cartilage could lead to chronic arthritis in TNF-transgenic mice, whereas inflammatory conditions might influence GDF5 expression via fibroblasts (inflammatory infiltration indicator) in osteoarthritis [31]. Therefore, we reasonably assumed that the GDF5 gene is potentially related to orthopedic CPSP.

A previous study by Zhang et al. suggests that GDF5 gene polymorphism is associated with knee osteoarthritis, and its interactions with age, BMI, and a history of drinking increase the risk [32]. Recently, a GWAS of

Table 5 Haplotype-based association analyses in the study

\begin{tabular}{|c|c|c|c|c|}
\hline \multirow[t]{2}{*}{ Haplotype } & \multicolumn{3}{|c|}{ Estimated frequencies (\%) } & \multirow{2}{*}{$\begin{array}{l}\text { Global } \\
P \text { value** }\end{array}$} \\
\hline & Case & Control & $P$ value* & \\
\hline \multicolumn{4}{|c|}{ rs143384-rs224335-rs739329 } & $<0.000001$ \\
\hline AGG & 80.27 & 75.95 & 0.00012 & \\
\hline GGG & 11.61 & 15.24 & 0.00010 & \\
\hline GAA & 3.78 & 4.48 & 0.19540 & \\
\hline GAG & 3.32 & 3.88 & 0.26244 & \\
\hline
\end{tabular}

Significant $P$ values are in bold italics. Haplotypes are not shown, if frequency less than $1 \%$

*Means based on 100,000 permutations

**Means based on comparison of frequency distribution of all haplotypes knee pain-related genes identified associations with rs143384 located in the GDF5 gene in the UK Biobank and identified the $\mathrm{A}$ allele as a risk factor [27]. The present study selected 8 tag SNPs in the GDF5 gene and found that the GDF5 gene is associated with orthopedic CPSP, among which the A allele of rs143384 in the 5' UTR of the GDF5 gene could significantly increase the CPSP risk. Our study showed the first investigation of the correlation between GDF5 and orthopedic CPSP in a Han Chinese population and suggested that interactions between the GDF5 gene and age, BMI, and drinking history increased orthopedic CPSP susceptibility. SNP rs143384 in the GDF5 gene was associated with CPSP in subsets aged $\leq 61$ years, while Zhang et al. found significant differences in the GDF5 gene polymorphism between knee osteoarthritis and the corresponding control group aged $>60$ years in the Asian population [32]. This inconsistency suggests that the samples should be further investigated by stratification according to the type of surgery. Upregulated GDF5 gene expression was observed in brown adipose tissues in obese mice, and its overexpression led to increased systemic energy expenditure [33], while the association between rs143384 and CPSP was only observed in subgroups with a BMI $\leq 26$. Although smoking history and pain history had no interaction with the GDF5 gene to affect orthopedic CPSP, a history of drinking did interact with the GDF5 gene to associate with orthopedic CPSP. The reason may be that 
alcohol affects nervous system sensitivity, while GDF5 gene expression is related to nerve synapses [12]. Furthermore, haplotype analyses in our study suggested that SNP rs143384 in GDF5 was significantly associated with CPSP susceptibility, and both haplotypes AGG and GGG (rs143384-rs224335-rs739329) were associated with CPSP risk.

Although few reports have investigated the association between the GDF5 gene and orthopedic CPSP, GDF5 gene expression and polymorphic markers affecting osteoarthritis pain, particularly joint pain, have been published in humans from different ethnic groups. In particular, the SNP rs143383 (T/C) in the 5'UTR of the GDF5 gene is a major susceptibility factor for osteoarthritis in Asian and European populations [17, 19, 34]. The allelic expression of rs143383 can lead to reduced GDF5 expression because the $\mathrm{CpG}$ sites formed by allele $\mathrm{C}$ of rs143383 are methylated in cells and joint tissues, and GDF5 is critical for joint homeostasis [20, 35]. Using luciferase reporter assays, Egli et al. suggest that the rs143384 SNP in the 5'UTR of the GDF5 gene interacts with rs143383 in vitro [28]. It is reasonable to believe that rs143384 may affect GDF5 gene expression and is associated with osteoarthritis and orthopedic CPSP. GDF5 encodes a secreted ligand of the TGF- $\beta$ superfamily [10] that regulates the growth of neuronal axons and dendrites, as well as tissue development, including cartilage and joints [11], and plays a role in the inflammatory response and tissue damage [12]. Functional studies suggest that GDF5 absence in mouse models profoundly affects knee morphology [36, 37]. As a functional protein, GDF5 supplementation has therapeutic potential in the chondrogenic process and maintenance of cartilage homeostasis [38]. Degenkolbe et al. indicate that the superagonistic GDF5 variant shows faster and more efficient bone defect healing in patients with multiple synostoses syndrome using an animal model [39]. Given that different GDF5 pathogenic mutations are related to different clinical features, the depression of GDF5 may result in bone development defects, and overexpression causes excessive bone formation [40]. The current study suggests that SNP rsl43384 in GDF5 is associated with orthopedic CPSP. The underlying mechanism may be that GDF5 gene expression influences the rate of healing of injured tissue after orthopedic surgery, and a proper healing rate usually reduces postsurgical pain. Although our study is based on a moderate sample size, some deficiencies should not be ignored. In particular, stratified analysis must be confirmed in other ethnic populations. Additionally, our study lacks functional data to elucidate the underlying interaction mechanisms between SNP rs143384 in GDF5 and orthopedic CPSP. Most importantly, the clinical symptoms of our samples should be considered to refine the correlation between rs143384 and the phenotype to determine the potential of these biomarkers in clinical applications.

Generally, our present findings, through several sets of analyses, suggest that rs143384 in the GDF5 gene is strongly associated with CPSP in the Han Chinese population and is a potential gene for CPSP sensitivity. However, the mechanism by which GDF5 affects CPSP remains unclear. In-depth investigation of the pathological mechanisms and fundamental role of GDF5 in CPSP is necessary and will facilitate potential clinical applications.

\begin{abstract}
Abbreviations
GDF5: Growth differentiation factor 5; CPSP: Chronic postsurgical pain; GWAS: Genome-wide association study; SNP: Single nucleotide

polymorphism; PCIA: Patient-controlled intravenous analgesia; PAS: Pain analog scale; MAF: Minor allele frequency; HWE: Hardy-Weinberg equilibrium; LD: Linkage disequilibrium; ORs: Odds ratios; Cl: Confidence interval
\end{abstract}

\section{Supplementary Information}

The online version contains supplementary material available at https://doi. org/10.1186/s13018-021-02549-5.

Additional file 1: Supplemental Table S1. Basic information of the SNPs selected for genotyping. Supplemental Table S2. The results of single SNP-based association analyses of the rest 7 SNPS.

\begin{abstract}
Acknowledgements
We would like to thank all the study participants for their cooperation.

Authors' contributions

Authors Suoliang Wang conceived and designed the study. Shaoyao Yan carried out candidate SNPs selection and statistical analyses. Shaoyao Yan, Huiyong Nie, Gang Bu, Weili Yuan, and Suoliang Wang conducted subject screening. Shaoyao Yan, Huiyong Nie, Gang Bu, and Weili Yuan contributed to the collection and preparation of control DNA samples. Shaoyao Yan wrote the paper. All authors read and approved the final manuscript.
\end{abstract}

\section{Funding}

This study was supported by the First Affiliated Hospital of Xi'an Jiaotong University Research Foundation (2017MS-05).

Availability of data and materials

Please contact the authors for reasonable requests.

\section{Declarations}

Ethics approval and consent to participate

Written informed consent was obtained from all participants prior to their participation. The research protocol was approved by the Ethics Committee of the First Affiliated Hospital of Xi'an Jiaotong University. The ethical approval was consistent with the standards of the Declaration of Helsinki.

Consent for publication

Not applicable.

\section{Competing interests}

The authors declare that they have no competing interests.

Received: 19 May 2021 Accepted: 9 June 2021

Published online: 01 July 2021

\section{References}

1. Young EE, Lariviere WR, Belfer I. Genetic basis of pain variability: recent advances. J Med Genet. 2012;49(1):1-9. https:/doi.org/10.1136/jmedgenet-2011-100386. 
2. Diatchenko L, Slade GD, Nackley AG, Bhalang K, Sigurdsson A, Belfer I, et al. Genetic basis for individual variations in pain perception and the development of a chronic pain condition. Hum Mol Genet. 2005;14(1):13543. https://doi.org/10.1093/hmg/ddi013.

3. Lacroix-Fralish ML, Mogil JS. Progress in genetic studies of pain and analgesia. Annu Rev Pharmacol Toxicol. 2009;49(1):97-121. https://doi.org/1 0.1146/annurev-pharmtox-061008-103222.

4. Werner MU, Kongsgaard UE. I. Defining persistent post-surgical pain: is an update required? Br J Anaesth. 2014;113(1):1-4.

5. A AJ, B LRA, C CSN, et al. Persistent postsurgical pain in a general population: prevalence and predictors in the Troms study. Pain. 2012; 153(7):1390-1396.

6. Weiser TG, Regenbogen SE, Thompson KD, Haynes AB, Lipsitz SR, Berry WR, et al. An estimation of the global volume of surgery: a modelling strategy based on available data. Lancet. 2008:372(9633):139-44. https://doi.org/10.1 016/50140-6736(08)60878-8.

7. Duan G, Xiang G, Zhang X, Yuan R, Zhan H, Qi D. A single-nucleotide polymorphism in SCN9A may decrease postoperative pain sensitivity in the general population. Anesthesiology. 2013;118(2):436-42. https://doi.org/10.1 097/ALN.0b013e31827dde74.

8. Ren $Z Y, X u X Q$, Bao YP, He J, Shi L, Deng JH, et al. The impact of genetic variation on sensitivity to opioid analgesics in patients with postoperative pain: a systematic review and meta-analysis. Pain Physician. 2015;18(2):131-52.

9. Motaghedi R, Bae JJ, Memtsoudis SG, Kim DH, Beathe JC, Paroli L, et al. Association of obesity with inflammation and pain after total hip arthroplasty. Clin Orthop Relat Res. 2014;472(5):1442-8. https:/doi.org/10.1007/s11999-013-3282-2.

10. Yi-Che $L$, Shih-Yuan $H$, Hung-Hsiang $L$, et al. Vitamin D can ameliorate chlorhexidine gluconate-induced peritoneal fibrosis and functional deterioration through the inhibition of epithelial-to-mesenchymal transition of mesothelial cells. Biomed Res Int. 2015;2015:595030.

11. Valdes AM, Evangelou E, Kerkhof $H$, et al. The GDF5 rs 143383 polymorphism is associated with osteoarthritis of the knee with genome-wide statistical significance. Ann Rheum Dis. 2011;70(5):873-5. https://doi.org/10.1136/ard.2010.134155.

12. Chen W, Meng J, Qian H, et al. A Study of IL-1 $\beta$, MMP-3, TGF- $\beta 1$, and GDF5 Polymorphisms and Their Association with Primary Frozen Shoulder in a Chinese Han Population. Biomed Res Int. 2017;2017:3681645.

13. Yau MS, Yerges-Armstrong LM, Liu Y, Lewis CE, Duggan DJ, Renner JB, et al. Genome-wide association study of radiographic knee osteoarthritis in North American Caucasians. Arthritis Rheumatol. 2017;69(2):343-51. https://doi. org/10.1002/art.39932.

14. Naureen Z, Lorusso L, Manganotti P, et al. Genetics of pain: from rare Mendelian disorders to genetic predisposition to pain. Acta Biomed. 2020; 91(13-S):e2020010.

15. Köberle B, Koch B, Fischer BM, et al. Single nucleotide polymorphisms in DNA repair genes and putative cancer risk. Arch Toxicol. 2016; 90(10):2369-2388.

16. Zhang $\mathrm{R}$, Yao J, Xu P, et al. A comprehensive meta-analysis of association between genetic variants of GDF5 and osteoarthritis of the knee, hip and hand. Inflamm Res. 2015; 64(6):405-14.

17. Miyamoto Y, Mabuchi A, Shi D, Kubo T, Takatori Y, Saito S, et al. A functional polymorphism in the 5 ' UTR of GDF5 is associated with susceptibility to osteoarthritis. Nat Genet. 2007;39(4):529-33. https://doi.org/10.1038/2005.

18. Valdes AM, Spector TD, Doherty S, Wheeler M, Hart DJ, Doherty M. Association of the DWWA and GDF5 polymorphisms with osteoarthritis in UK populations. Ann Rheum Dis. 2009;68(12):1916-20. https://doi.org/10.113 6/ard.2008.102236

19. Liu J, Cai W, Zhang H, He C, Deng L. Rs143383 in the growth differentiation factor 5 (GDF5) gene significantly associated with osteoarthritis (OA)-a comprehensive meta-analysis. Int J Med Sci. 2013;10(3):312-9. https://doi. org/10.7150/ijms.5455.

20. Syddall CM, Reynard LN, Young DA, et al. The identification of trans-acting factors that regulate the expression of GDF5 via the osteoarthritis susceptibility SNP rs143383. Plos Genet. 2012;20(supp-S1):S46-S7.

21. Shin MH, Lee SJ, Kee SJ, Song SK, Kweon SS, Park DJ, et al. Genetic association analysis of GDF5 and ADAM12 for knee osteoarthritis. Joint Bone Spine. 2012;79(5):488-91. https://doi.org/10.1016/j.jbspin.2011.10.016.

22. Tsezou A, Satra M, Oikonomou P, et al. The growth differentiation factor 5 (GDF5) core promoter polymorphism is not associated with knee osteoarthritis in the Greek population. J Orthop Res. 2010;26(1):136-40.

23. Zhao L, Pan H, Wang J, Cheng Z, Cheng LF, Wang BB, et al. Two single nucleotide polymorphisms in the GDF5 gene are associated with development dysplasia of the hip in Chinese female population. Sci China Life Sci. 2013;56(11):1063-5. https://doi.org/10.1007/s11427-013-4514-0.

24. Rice DA, Kluger MT, McNair PJ, et al. Persistent postoperative pain after total knee arthroplasty: a prospective cohort study of potential risk factors. Br J Anaesth. 2018;121(4):804-12. https://doi.org/10.1016/j.bja.2018.05.070.

25. Perrot $\mathrm{S}$, Laroche F, Marie P, Payen-Champenois $C$. Are there risk factors for musculoskeletal procedural pain? A national prospective multicentre study of procedural instantaneous pain and its recall after knee and spine injections. Joint Bone Spine. 2011;78(6):629-35. https:/doi.org/10.1016/j.jbspin.2011.02.006.

26. Pinto PR, Mclntyre T, Ferrero R, Almeida A, Araújo-Soares V. Risk factors for moderate and severe persistent pain in patients undergoing total knee and hip arthroplasty: a prospective predictive study. Plos One. 2013;8(9):e73917. https://doi.org/10.1371/journal.pone.0073917.

27. Meng W, Adams MJ, Palmer CNA, et al. Genome-wide association study of knee pain identifies associations with GDF5 and COL27A1 in UK Biobank. Commun Biol. 2019;2(1):321. https://doi.org/10.1038/s42003-019-0568-2.

28. Egli RJ, Southam L, Wilkins JM, Lorenzen I, Pombo-Suarez M, Gonzalez A, et al. Functional analysis of the osteoarthritis susceptibility-associated GDF5 regulatory polymorphism. Arthritis Rheumatol. 2009;60(7):2055-64. https:// doi.org/10.1002/art.24616.

29. Hoofwijk D, Fiddelers A, Peters ML, et al. Prevalence and predictive factors of chronic postsurgical pain and poor global recovery 1 year after outpatient surgery. Clin J Pain. 2015;31(12):1017-25. https://doi.org/10.1 097/AJP.00000000000000207.

30. Robinson WH, Lepus CM, Wang Q, et al. Low-grade inflammation as a key mediator of the pathogenesis of osteoarthritis. Nat Rev Rheumatol. 2016; 12(10):580-92.

31. Bramlage $C P$, Kaps $C$, Ungethüm U, Bramlage P, Koziolek M, Wessels J, Krenn V, Pruß A, Müller GA, Strutz F, Burmester GR, Häupl T. Modulatory effects of inflammation and therapy on GDF-5 expression in rheumatoid arthritis synovium. Scand J Rheumatol. 2008;37(6):401-9. https://doi.org/10.1 080/03009740802120010.

32. Zhang $\mathrm{S}$, Wang J, Ji H, et al. Interaction between GDF5 gene polymorphisms and environment factors increased the risk of knee osteoarthritis: a case-control study. Biosci Rep. 2019;39(2):BSR20182423.

33. Hinoi E, Nakamura Y, Tak Ad AS, et al. Growth differentiation factor-5 promotes brown adipogenesis in systemic energy expenditure. Diabetes. 2014;63(1):162-75. https://doi.org/10.2337/db13-0808.

34. Kay C, Atsushi T, Ingrid M, et al. A meta-analysis of European and Asian cohorts reveals a global role of a functional SNP in the 5' UTR of GDF5 with osteoarthritis susceptibility. Hum Mol Genet. 2008;17(10):1497-504.

35. Reynard LN, Catherine B, Canty-Laird EG, et al. Expression of the osteoarthritis-associated gene GDF5 is modulated epigenetically by DNA methylation. Hum Mol Genet. 2011;20(17):3450-60.

36. Pregizer SK, Kiapour AM, Young M, et al. Impact of broad regulatory regions on Gdf5 expression and function in knee development and susceptibility to osteoarthritis. Ann Rheum Dis. 2018;77(3):450.

37. Capellini TD, Chen H, Cao J, Doxey AC, Kiapour AM, Schoor M, et al. Ancient selection for derived alleles at a GDF5 enhancer influencing human growth and osteoarthritis risk. Nat Genet. 2017:49(8):1202-10. https://doi.org/10.1038/ng.3911.

38. Sun K, Guo J, Yao X, Guo Z, Guo F. Growth differentiation factor 5 in cartilage and osteoarthritis: a possible therapeutic candidate. Cell Prolif. 2021;54(3):e12998. https://doi.org/10.1111/cpr.12998.

39. Degenkolbe E, Schwarz C, Ott CE, König J, Schmidt-Bleek K, Ellinghaus A, et al. Improved bone defect healing by a superagonistic GDF5 variant derived from a patient with multiple synostoses syndrome. Bone. 2015;73: 111-9. https://doi.org/10.1016/j.bone.2014.12.017.

40. Genovesi ML, Guadagnolo D, Marchionni E, Giovannetti A, Traversa A, Panzironi N, et al. GDF5 mutation case report and a systematic review of molecular and clinical spectrum: Expanding current knowledge on genotype-phenotype correlations. Bone. 2021;144:115803. https://doi.org/1 0.1016/j.bone.2020.115803.

\section{Publisher's Note}

Springer Nature remains neutral with regard to jurisdictional claims in published maps and institutional affiliations. 